\title{
Depletion of Dopamine in the Caudate Nucleus But Not in Nucleus Accumbens Impairs Reaction-Time Performance in Rats
}

\author{
M. Amalric and G. F. Koob' \\ ${ }^{1}$ Preclinical Neuroscience and Endocrinology, Scripps Clinic and Research Foundation, La Jolla, California 92037, and \\ Laboratoire de Neurobiologie et Neuropharmacologie du Developpement, Université de Paris-Sud, Orsay 91405, France
}

\begin{abstract}
Impairment of the dopaminergic system in the brain induced by dopamine-receptor antagonists or by specific neurotoxin terminal lesions results in motor disturbances in rats. In order to specify further the role of the different dopamine pathways in the brain on motor function, the performance of rats trained in an operant reaction-time task was examined after systemic administration of a dopamine-receptor antagonist, $\alpha$-flupenthixol, and after specific destruction of dopamine neurons by 6-hydroxydopamine perfusion into the nucleus accumbens or caudate nucleus. Rats were trained to press a lever and release it as quickly as possible after a lightcue conditioned stimulus (CS). Reaction time was measured from the CS to the release of the lever for each trial. $\alpha$-Flupenthixol $(0.2$ and $0.4 \mathrm{mg} / \mathrm{kg}$ ) injected intraperitoneally impaired the reaction-time performance of the rats. While disruption of dopamine activity in the nucleus accumbens did not affect the performance of the rats, lesions of the dopamine terminals of the nigrostriatal pathway in the corpus striatum (59\% decrease in posterior striatal dopamine) significantly impaired reaction-time performance. These results show that moderate decreases in dopamine function restricted to the corpus striatum can disrupt sensitive motor performance, and support the hypothesis that dopamine in the corpus striatum has a role in the initiation of complex goal-directed responses.
\end{abstract}

The large-scale inactivation of central nervous system dopamine function with dopamine-receptor antagonists and midbrain neurotoxin lesions results in a behavioral syndrome not unlike severe Parkinson's disease in man. Rats show akinesia, catalepsy, and are impaired in performance in a variety of behavioral situations (John and Killam, 1959; Fibiger et al., 1974; Koob et al., 1984).

Rats are particularly impaired in the acquisition of avoidance behavior in which the animal must make a response to a conditioned stimulus (CS) that predicts an aversive event, such as

\footnotetext{
Received Sept. 23, 1986; revised Jan. 20, 1987; accepted Jan. 26, 1987.

This is publication number $4521 \mathrm{BCR}$ from the Research Institute of Scripps Clinic, La Jolla, CA. We thank Dr. Floyd Bloom for his helpful comments on the manuscript. We gratefully thank Mr. Robert Lintz for his programming assistance Ms. Lynne Randolph for performing all catecholamine determinations, and the BCR Word Processing Center for manuscript preparation. This work was supported in part by National Institute on Drug Abuse Grant 03665 and National Institute on Alcohol Abuse and Alcoholism Grant AA06420. M.A. was supported by grants from the Fondation pour la Recherche Medicale and the Fondation Del Duca.

Correspondence should be addressed to George F. Koob, Scripps Clinic and Research Foundation BCR1, 10666 N. Torrey Pines Road, La Jolla, CA 92037. Copyright (C) 1987 Society for Neuroscience $0270-6474 / 87 / 072129-06 \$ 02.00 / 0$
}

an electrical shock. Dopamine-receptor antagonists (John and Killam, 1959), intraventricular injection of 6-hydroxydopamine (Cooper et al., 1973), and lesions of the nigrostriatal dopamine system (Fibiger et al., 1974) all dramatically impair acquisition of an active avoidance response. These deficits are reversed by L-DOPA treatment (Zis et al, 1974) and appear to depend on a large depletion of dopamine in both major projections of the midbrain dopamine system, the mesocorticolimbic and nigrostriatal dopamine systems (Koob et al., 1984).

Dopamine-receptor antagonists disrupt other types of motor control in rats (Falk, 1969; Fowler et al., 1984), but comparatively little work has been directed to the exploration of the specific role of dopamine pathways in reaction-time performance in animals. Dopamine-receptor antagonists produce increases in reaction time in man (Spohn et al., 1985), and patients with Parkinson's disease also show significant increases in reaction time (Conde et al., 1981; Evarts et al., 1981).

The purpose of the present study was (1) to examine the effects of systemic dopamine-receptor blockade on performance in an operant reaction-time task, and (2) to examine whether depletion of striatal or accumbens dopamine could mimic any of the effects of the CNS dopamine-receptor blockade.

\section{Materials and Methods}

Subjects. Twenty-seven male albino Wistar rats (Charles River Laboratories), weighing 160-180 gm, were housed in groups of 3 and maintained on a $12 \mathrm{hr}$ light cycle with lights on at 7 A.M. Rats were first deprived of food for $48 \mathrm{hr}$, then maintained at $\sim 80 \%$ of the weight of free-feeding rats by restricting the amount of food ration provided after the daily experimental session to $15 \mathrm{gm} / \mathrm{d} / \mathrm{rat}$. No difference in weight between sham and experimental animals was observed. Weights at the end of the experiment ranged from 320 to $380 \mathrm{gm}$.

Apparatus. Four operant chambers $(25 \times 30 \times 27.5 \mathrm{~cm})$ were used. They werc constructed of aluminum with grid floors. Each chamber was supplied with a food-pellet dispenser (model D-1; Ralph Gerbrands Co., Arlington, MA) located centrally behind one of the shorter walls, and with a retractable lever (model RRL-005; BRS/LVE Division of Technical Service Inc., Beltsville, MD), requiring a force of $0.12 \mathrm{~N}$ for switch closure and located $2.5 \mathrm{~cm}$ to the right of the reinforcement tray and $3.0 \mathrm{~cm}$ from the grid floor.

Procedure. Animals were first trained to lever-press for food on a continuous reinforcement schedule until they obtained 100 pellets. They were then trained on a reaction-time paradigm modified from Conde et al. (1978). The task consisted of pressing down on a lever and releasing it as quickly as possible (reaction time) after a light-cue conditioned stimulus (CS: 3 flashing lights located above the lever).

Rats initiated the trial by pressing the lever, then waiting for the CS for a variable period of time (delays). Four different time periods $\left(D_{1}-\right.$ $0.25, \mathrm{D}_{2}=0.5, \mathrm{D}_{3}=1.0, \mathrm{D}_{4}=2.0 \mathrm{sec}$ ) could be delivered at random preceding the CS. If the rats failed and released the lever before the light (anticipation), no reward was given and a new trial was initiated. If the rats met this first criterion, they then had to release the lever within 1 


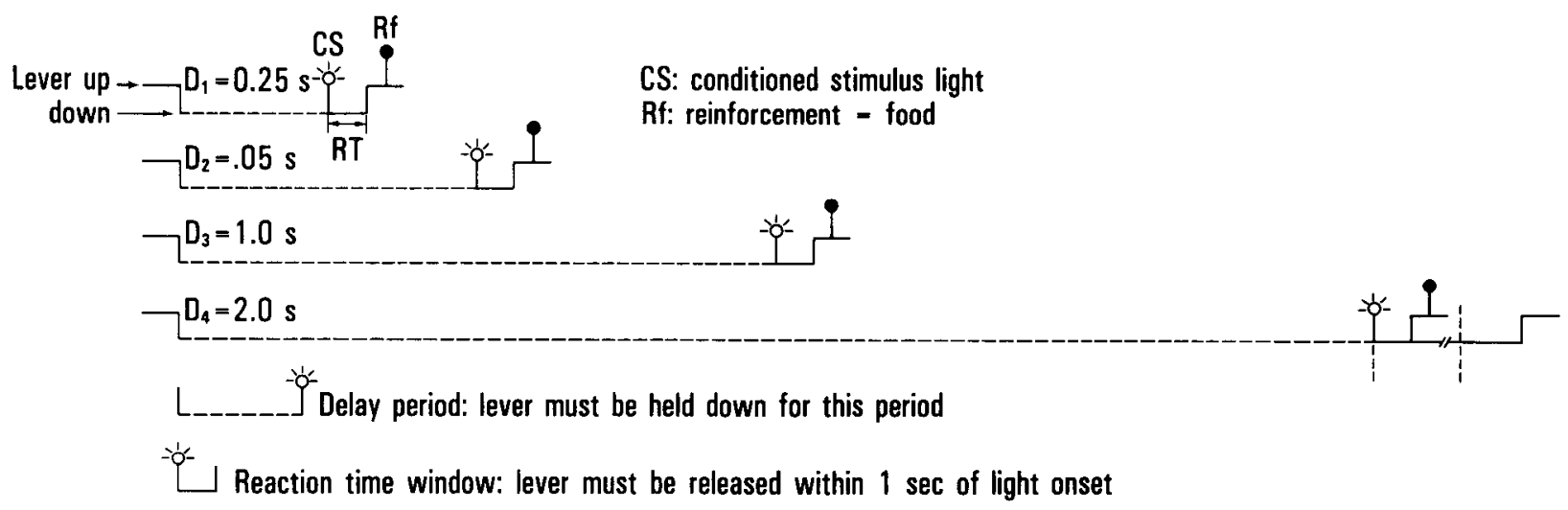

Figure 1. Schematic representation of the testing proccdurc. Rats started a trial by pressing the lever down and waiting for a conditioned stimulus $(C S)$, i.e., 3 flashing lights located above the lever. The waiting period could vary at random from 0.25 to 2.0 sec $\left(4\right.$ different delays: $D_{1}=0.25$, $\mathrm{D}_{2}=0.5, \mathrm{D}_{3}=1.0, \mathrm{D}_{4}=2.0 \mathrm{sec}$ ). If the rat failed and released the lever before the light, no reward was given and a new trial had to be initiated. If the ral succeeded in this first criterion, the light would come on and the rat had to release the lever within 1 sec in order to be reinforced. The time period from the CS to the lever release was measured as the reaction time $(R T)$. The positive reinforcer $(R f)$ was a $45 \mathrm{mg}$ Noyes food pellet delivered at each successful trial. The session ended after 100 trials.

sec after the CS onset to be reinforced with a food pellet. The lights would stay on until the release of the lever within the $1 \mathrm{sec}$ period. The time period from CS onset to lever-release detection was measured as the reaction time. The positive reinforcer was a $45 \mathrm{mg}$ Noyes food pellet delivered for each successful trial (see Fig. 1). There was no house light in the operant chamber.

The session ended after 100 trials. Animals were trained every day between 12 A.M. and 2 P.M., 5 d/week. A stable baseline (criterion: $85 \%$ of reaction times were within the $1 \mathrm{sec}$ restriction) was obtained after $25-30$ sessions.

Experiment 1 . After the training sessions, rats were injected intraperitoneally for $4 \mathrm{~d}$ with a saline solution $(0.9 \%$ sodium chloride; $1 \mathrm{ml} / \mathrm{kg})$ $2 \mathrm{hr}$ before each daily session. On the fifth day, rats were divided into 4 groups of equal levels of performance (i.e., rats with low or very high percentagcs of successful reaction times were counterbalanced in each group) and received 4 different doses of $\alpha$-flupenthixol $(0.0,0.1,0.2$, and $0.4 \mathrm{mg} / \mathrm{kg}$, i.p.) $21 / 2 \mathrm{hr}$ before testing ( $n=7 /$ group, except for 0.4 $\mathrm{mg} / \mathrm{kg}$, where $n=6$ ). They were then tested in the operant chambers for their reaction-time performance.

Experiment $I I$. The same animals were divided into 3 groups, with the same proportion of rats showing good ( $80 \%$ success) or moderate ( $50 \%$ success) performance, and were evenly distributed according to the dose of $\alpha$-flupenthixol previously administered. They were then prepared for surgery. The rats were anesthetized with pentobarbital (50 $\mathrm{mg} / \mathrm{kg}$, i.p.) and secured in a Kopf stereotaxic instrument with the tooth bar $5 \mathrm{~mm}$ above the interaural line. One group $(n=8)$ received bilateral injection of 6-OHDA (6-hydroxydopamine; $8 \mu \mathrm{g} / 2 \mu \mathrm{l}$, expressed as free base) dissolved in saline containing ascorbic acid $(0.1 \mathrm{mg} / \mathrm{kg})$ into the nucleus accumbens. 6-OHDA was injected through a 30 -gauge cannula bilaterally into the nucleus accumbens at a rate of $1 \mu \mathrm{l} / 3 \mathrm{~min}$ (coordinates: anteroposterior (AP) + 3.2 from bregma; mediolateral (ML) \pm 1.7; dorsoventral (DV) - 7.8 from skull surface). A second group $(n=$ 8) received bilateral injections of 6-OHDA into the caudate nucleus following the same procedure (coordinates: AP + 1.8 from bregma; $\mathrm{ML} \pm 2.8 ; \mathrm{DV}-5.5$ from skull surface).

The third group was divided into 2 control subgroups (sham), which received bilateral injections of vehicle alone $(2 \mu 1)$ either into the nucleus accumbens $(n=6)$ or into the caudate nucleus $(n=5)$. All the rats were allowed 1 week to recover after surgery and were maintained with 20 $25 \mathrm{gm}$ food per rat $/ \mathrm{d}$.

The baseline tested during the 4 previous sessions for the 3 different groups before surgery served as the control for the lesion effect. All rats wcre then tested on the reaction-time procedure for 4 subsequent sessions.

Data analysis. Results were expressed as the percentage success of the reaction time (i.e., numbers of lever releases occurring within the reaction-time limit, divided by the number of $C S$ ). For each session, mean correct reaction time in milliseconds was also calculated. All long reaction times (above $1 \mathrm{sec}$ ) were also analyzed separately.

For experiment $I$, the percentage scores were subjected to a 3 -factor analysis of variance (ANOVA) with repeated measures on 2 factors. The drug groups constituted the independent factor (dose), the sessions pre- and postdrug were the first dependent factor (session), and the 4 different delays were the second dependent factor (delay). Individual means were compared using a paired $t$ test. After no significant differences in performance for the 4 different delays were observed, we analyzed the mean reaction time before drug treatment (mean of the 4 baseline sessions) and during the test day with a 2-way ANOVA, with the drug groups (dose) forming the independent factor, and sessions preand postdrug forming the dependent factor. For reaction times above the $1 \mathrm{sec}$ limit, an ANOVA was calculated using a log transformation to maintain homogeneity of error variance between the means (Wincr, 1971).

For experiment II, the percentage scores were analyzed with a 3-factor ANOVA, where the independent factor was lesion group, the sessions prelesion ( $4 \mathrm{~d}$ ) and postlesion (4 d) formed the first dependent factor, and the second dependent factor was delay. Individual group comparisons within a factor were analyzed using a Newman-Keuls a posteriori test (Winer, 1971). Data from the sham animals for the nucleus accumbens and corpus striatum were not significantly different from each other and were pooled for comparison with the lesion groups.

Because of the possibility of inherently skewed distribution of percent scores (Winer, 1971), all ANOVAs were recalculated using an arcsin transformation. However, such transformed ANOVAs did not differ significantly from the calculations using the raw data and are therefore not reported. Means of correct reaction time (within $1 \mathrm{scc}$ ) werc obtaincd for all rats on each session pre- and postlesion and subjected to a 2 -factor ANOVA (lesion group was the independent factor and performance by sessions pre- and postlesion the dependent factor).

At the end of the experiment, all the 6-OHDA-injected rats and the sham animals were decapitated and forebrain structures [anterior caudate $(\mathrm{AC})$, posterior caudate (PC), and nucleus accumbens (N. Acc.)] were removed from coronal slices and stored at $-40^{\circ} \mathrm{C}$ until assayed for dopamine and dihydroxyphenylacetic acid (DOPAC) using electrochemical detection following separation by high-pressure liquid chromatography (Felice et al., 1978). The anterior caudate was defined as the portion of the corpus striatum taken from the coronal cut containing the nucleus accumbens and was located dorsal to the nucleus accumbens. The posterior striatum was defined as any striatal tissue posterior to the coronal slice containing the nucleus accumbens (see also Koob ct al., 1984).

\section{Results}

Treatment with $\alpha$-flupenthixol significantly impaired the performance of the rats, as measured by a decrease in the percentage of correct trials (see Fig. 2). Analysis of variance revealed a significant dose $\times$ session interaction $(F=4.888, d f=3.23, p<$ $0.05)$. There were no significant interactions with delay $(F<1)$. 

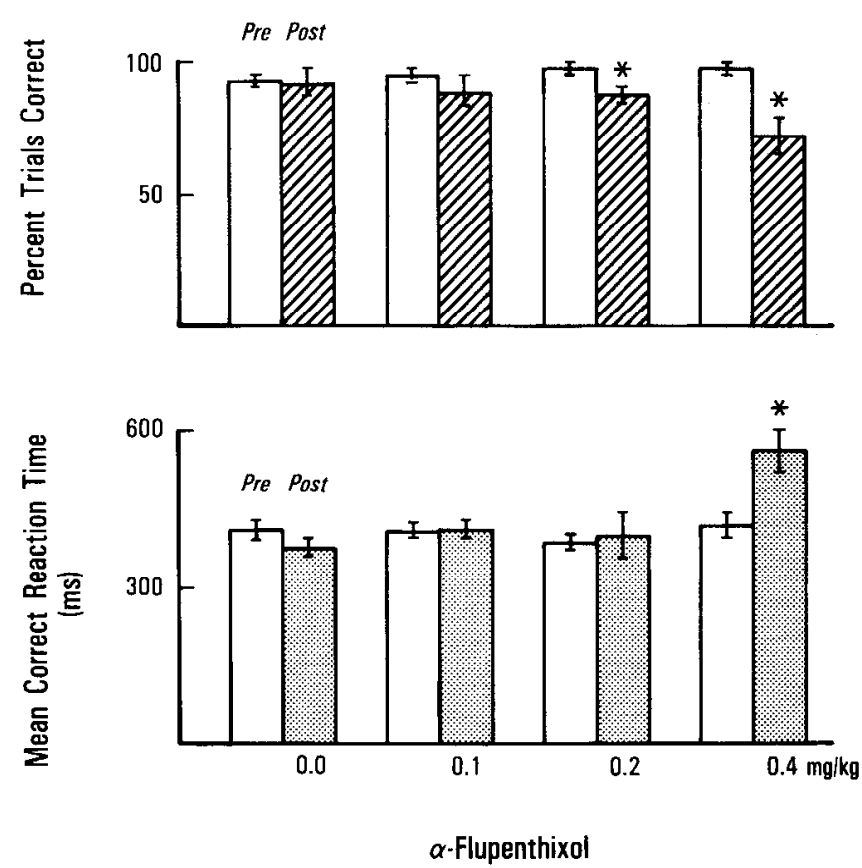

Figure 2. Reaction-time performance after $\alpha$-flupenthixol treatment. Effects of $\alpha$-flupenthixol pretreatment $(0.0,0.1,0.2$, and $0.4 \mathrm{mg} / \mathrm{kg})$ on reaction-time performance. Pre, The mean \pm SEM of the rats' performance on reaction time during the 4 sessions preceding $\alpha$-flupenthixol testing. Post, Rats' performance on reaction time during the test day. Top, Percentage of trials correct (successful trials divided by number of trials presented). Bottom. Mean reaction time in milliseconds. Each group of rats was injected with one dose of $\alpha$-flupenthixol $2.5 \mathrm{hr}$ before testing; $n=7$ except for the $0.4 \mathrm{mg} / \mathrm{kg}$ dose, where $n=6$. Asterisks, Significantly different from Pretest values $(p<0.05$; paired $t$ test).

Individual comparisons of means, using a paired $t$ test, showed that the 0.2 and $0.4 \mathrm{mg} / \mathrm{kg}$ doses significantly reduced the percentage of correct scores, as compared to baseline performance. Reaction time during correct trials increased with $\alpha$-flupenthixol (see Fig. 2), as shown by a significant interaction between dose and session (ANOVA: $F=7.64, d f=3.23, p<0.05$ ). At the highest dose $(0.4 \mathrm{mg} / \mathrm{kg})$, the mean reaction time showed a significant increase of $150 \mathrm{msec}[t($ pair $)(d f=5)=3.44]$. Reaction times of the incorrect trials (i.e., reaction times above the $1 \mathrm{sec}$ limit) also increased with the higher doses of $\alpha$-flupenthixol (see Table 1A), as revealed by the ANOVA following log transformation $(F=3.07, d f=3.23, p<0.05)$.
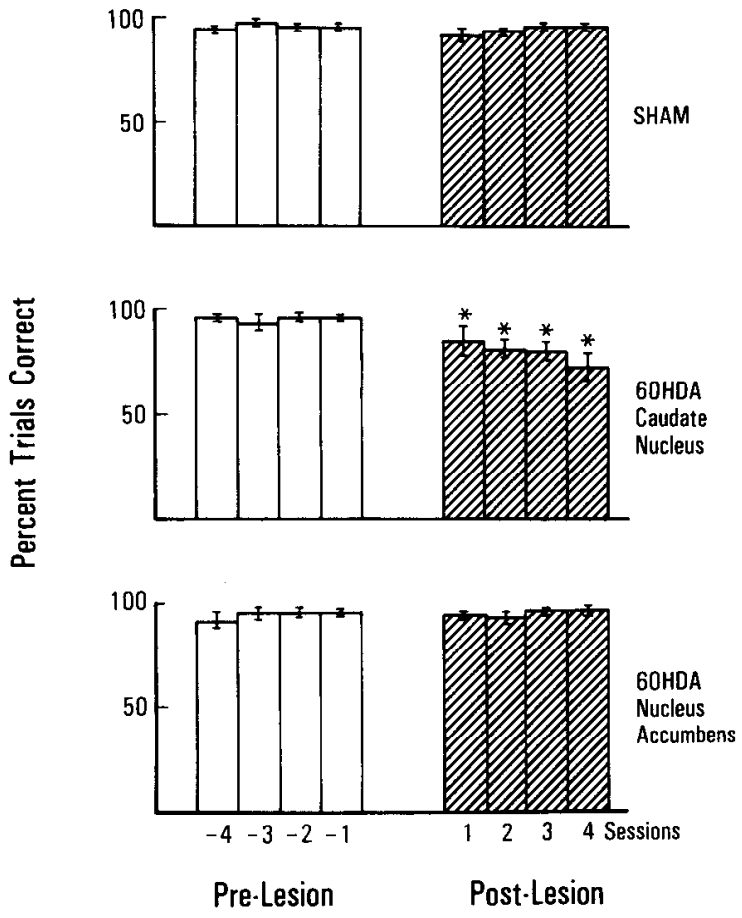

Figure 3. Reaction-time performance after 6-OHDA lesions. Performance of the rats on reaction time after 6-OHDA lesions either in the caudate nucleus $(n=8)$ or the nucleus accumbens $(n=8)$. Sham animals were infused with vehicle (ascorbic acid plus saline) either in the nucleus accumbens $(n=6)$ or the caudate nucleus $(n=5)$. Data for the 2 groups are presented together. Baseline is the mean of the percentage of successful trials \pm SEM during the 4 sessions preceding surgery. One week after surgery all rats were tested for 4 sessions. Asterisks, Significant difference between postlesion and baseline performance $(p<0.05$; Newman-Keuls test).

While these results are significant, they represent only a part of the behavioral effects of $\alpha$-flupenthixol. The drug also significantly decreased the number of trials attempted by the rats (see Table 1B). In effect, the rats stopped responding before the end of the session at the higher doses of $\alpha$-flupenthixol.

Effects similar to those observed with $\alpha$-flupenthixol were seen after a 6-OHDA lesion of the caudate nucleus, but not of the nucleus accumbens (see Fig. 3). Analysis of variance revcalcd a significant lesion $\times$ session interaction $(F=10.48, d f=2.24$, $p<0.05$ ). Subsequent analysis within the caudate group showed

Table 1. Incorrect trials (lever releases above $1000 \mathrm{msec}$ criterion)

Dose $(\mathrm{mg} / \mathrm{kg})$

\begin{tabular}{lcccc} 
& & & & \\
Sessions & 0 & 0.1 & 0.2 & 0.4 \\
\hline A. Mean reaction time (misec) & \pm SEM & and number of trials & before and after $\alpha$-flupenthixol administration \\
Are & $2232 \pm 202$ & $2006 \pm 112$ & $2635 \pm 495$ & $2482 \pm 285$ \\
Trials & 5 & 3 & 2 & 2 \\
Post & $2932 \pm 486$ & $2300 \pm 350$ & $9614 \pm 4007^{*}$ & $7372 \pm 3195^{*}$ \\
$\quad$ Trials & 5 & 8 & 6 & 6 \\
B. Mean number of lever presses before and after $\alpha$-flupenthixol administration & \\
Pre & 100 & 100 & 100 & 100 \\
Post & 100 & 100 & $79 \pm 10$ & $37 \pm 8^{*}$ \\
\hline
\end{tabular}

${ }^{a} n=7 ;$ for $0.4 \mathrm{mg} / \mathrm{kg}, n-6$.

${ }^{*} p<0.05$ (paired $t$ test), significantly different from Pretest values. 

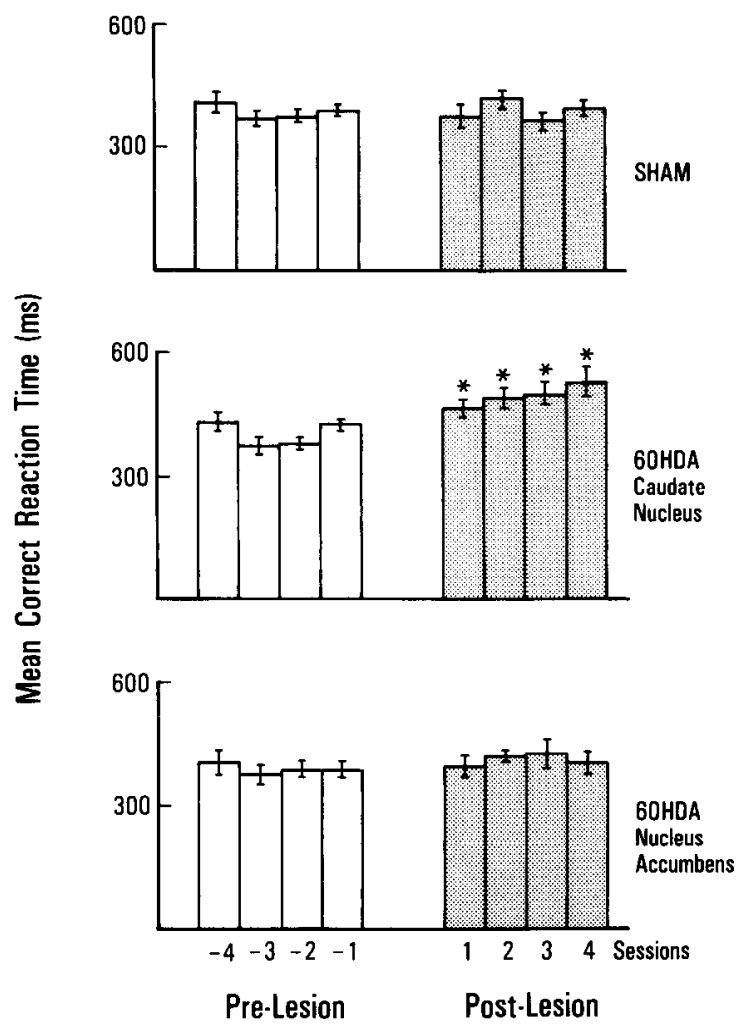

Figure 4. Mean reaction time after 6-OHDA lesions. Mean reaction time in milliseconds $( \pm$ SEM) before and after 6-OHDA lesions in the caudate nucleus $(n=8)$ or the nucleus accumbens $(n=8)$. Sham animals, same as in Figure 3. Asterisks, Significant difference between postlesion baseline reaction time ( $p<0.05$; Newman-Keuls test).

that performance on sessions 1-4 postlesion was significantly decreased compared to baseline performance (Newman-Keuls test; $p<0.05$ ) (see Fig. 3). The rats in the lesion groups completed all sessions and failed to show the decrease in the number of trials completed observed in the rats treated with $\alpha$-flupenthixol. While reaction times were not modified in the rats with a nucleus accumbens lesion, an increase in reaction time of 30 $\mathrm{msec}$ in the first postlesion session and of 100-120 msec for the following postlesion sessions was observed for the group with a caudate lesion (see Fig. 4). Analysis of variance revealed a significant group $\times$ sessions interaction $(F=8.03, d f=2.24$, $p<0.05$ ). While the reaction time of incorrect trials did not significantly increase ( $F<1$ following log transformation), the number of incorrect lever releases increased for the rats with a 6-OHDA lesion of the caudate nucleus (see Table 2).

Biochemical analysis of the brains of rats with 6-OHDA lesions of the nucleus accumbens (see Table 3 ) revealed a $75 \%$ depletion of dopamine, a $67 \%$ depletion of DOPAC-recorded as nanograms per milligram protein in the nuclear accumbensand depletions of $50 \%$ of dopamine and $46 \%$ of DOPAC in the anterior caudate, as compared to unlesioned animals. No significant depletion (9\%) of dopamine or DOPAC was observed in the posterior caudate in this group. Animals with 6-OHDA lesions of the caudate nucleus (see Table 3) showed a $59 \%$ depletion of dopamine and a $43 \%$ depletion of DOPAC in the posterior caudate, but only a $17.3 \%$ depletion of dopamine and a $3.3 \%$ depletion of DOPAC in the anterior caudate. No significant changes in dopamine and DOPAC levels as compared to control were revealed in the nuclear accumbens for these animals.

\begin{tabular}{|c|c|c|c|}
\hline \multirow[b]{2}{*}{ Sessions } & \multicolumn{3}{|l|}{ Group } \\
\hline & $\begin{array}{l}\text { Sham } \\
(\mathrm{RT} \pm \mathrm{SE})\end{array}$ & $\begin{array}{l}\text { 6-OHDA, } \\
\text { caudate n. } \\
(\mathrm{RT} \pm \mathrm{SE})\end{array}$ & $\begin{array}{l}\text { 6-OHDA, } \\
\text { n. accumbens } \\
(\mathrm{RT} \pm \mathrm{SE})\end{array}$ \\
\hline \multicolumn{4}{|l|}{ Pre } \\
\hline-4 & $\begin{array}{c}2387 \pm 442 \\
4\end{array}$ & $\begin{array}{c}3857 \pm 1153 \\
3\end{array}$ & $\begin{array}{c}2651 \pm 306 \\
5\end{array}$ \\
\hline-3 & $\begin{array}{c}2450 \pm 281 \\
3\end{array}$ & $\begin{array}{c}5475 \pm 2250 \\
4\end{array}$ & $\begin{array}{c}2725 \pm 269 \\
3\end{array}$ \\
\hline-2 & $\begin{array}{c}3696 \perp 692 \\
3\end{array}$ & $\begin{array}{c}2798 \pm 616 \\
3\end{array}$ & $\begin{array}{c}2491 \\
3\end{array}$ \\
\hline-1 & $\begin{array}{c}2447 \pm 408 \\
4\end{array}$ & $\begin{array}{c}2447 \pm 626 \\
2\end{array}$ & $\begin{array}{c}2544+250 \\
3\end{array}$ \\
\hline \multicolumn{4}{|l|}{ Post } \\
\hline 1 & $\begin{array}{c}3238 \pm 365 \\
4\end{array}$ & $\begin{array}{c}2356 \pm 229 \\
10\end{array}$ & $\begin{array}{c}2101 \pm 319 \\
4\end{array}$ \\
\hline 2 & $\begin{array}{c}2531 \\
4\end{array}$ & $\begin{array}{c}3116 \pm 533 \\
11\end{array}$ & $\begin{array}{c}2319 \pm 267 \\
5\end{array}$ \\
\hline 3 & $\begin{array}{c}2427 \\
3\end{array}$ & $\begin{array}{c}3036 \pm 403 \\
10\end{array}$ & $\begin{array}{c}2471 \pm 346 \\
3\end{array}$ \\
\hline 4 & $\begin{array}{c}3077 \pm 568 \\
3\end{array}$ & $\begin{array}{c}2966 \pm 425 \\
17\end{array}$ & $\begin{array}{c}2885 \\
4\end{array}$ \\
\hline
\end{tabular}

\section{Discussion}

These experiments show that systemic administration to rats of the dopamine-receptor antagonist $\alpha$-flupenthixol disrupted performance in an operant reaction-time task. This deficit in reaction time reflected an overall deficit in performance, as manifested by a complete cessation of responding after 37 trials at the $0.4 \mathrm{mg} / \mathrm{kg}$ dose. However, the rats appeared to still be motivated by the food reinforcement, as they ate food pellets delivered by the experimenter. Previous work using a discriminative motor control task has shown similar performance deficits in rats (Falk, 1969; Fowler et al., 1984). In these studies, chlorpromazine, haloperidol, and clozapine produced dose-related decreases in time spent on the task (the amount of time the animal was in contact with a force transducer that had to be pressed for a minimum of $2 \mathrm{sec}$ to obtain a reinforcer), and decreases in the number of reinforcers obtained (Fowler et al., 1984).

In an attempt to localize the neuroanatomical site for this dopamine-receptor antagonistic effect, the rats were subjected to lesions of each of 2 of the major terminal projections of the midbrain dopamine systems, the nucleus accumbens and the corpus striatum. Lesions of the nucleus accumbens failed to alter reaction-time performance at any time postlesion. In contrast, denervation of dopamine in the caudate nucleus significantly impaired performance $7 \mathrm{~d}$ postlesion, and the deficit appeared to become more pronounced over sessions. This deficit in performance in the lesion rats was not accompanied by a general disruption in the ability to perform the task, and the rats continued to complete all sessions.

The difference between the 2 lesion groups cannot be explained by a simple difference in relative dopamine depletion in the 2 regions, since the rats with lesions of the nucleus accumbens actually had a larger depletion (75\%) than the rats with caudate lesions (59\%). Indeed, an important aspect of the pres- 
Table 3. Levels of dopamine and DOPAC in posterior caudate (PC), anterior caudate (AC), and nucleus accumbens (N. Acc.) following injection of 6-OHDA

\begin{tabular}{llll} 
Site & & Dopamine $^{a}$ & DOPAC \\
\hline Caudate nucleus lesion & & & \\
N. Acc. & & & \\
Sham 6-OHDA & $(n=5)$ & $63.92 \pm 4.0$ & $26.72 \pm 2.0$ \\
6-OHDA & $(n=8)$ & $66.69 \pm 3.8$ & $25.93 \pm 1.9$ \\
Depletion (\%) & & 1.0 & 2.9 \\
PC & & \\
Sham 6-OHDA & $(n=5)$ & $92.23 \pm 6.0$ & $13.45 \pm 0.4$ \\
6-OHDA & $(n=8)$ & $37.89 \pm 6.1^{*}$ & $7.60 \pm 0.6^{*}$ \\
Depletion (\%) & & 59 & 43 \\
AC & & & \\
Sham 6-OHDA & $(n=5)$ & $108.02 \pm 2.4$ & $19.14 \pm 1.4$ \\
6-OHDA & $(n=8)$ & $88.60 \pm 10.8$ & $18.52 \pm 0.9$ \\
Depletion (\%) & & 17.9 & 3.3 \\
Nucleus accumbens lesion & & \\
N. Acc. & & & \\
Sham 6-OHDA & $(n=6)$ & $64.72 \pm 1.8$ & $28.51 \pm 2.8$ \\
6-OHDA & $(n=8)$ & $16.46 \pm 2.9^{*}$ & $9.48 \pm 4.4^{*}$ \\
Depletion (\%) & & 75 & 67 \\
PC & & & \\
Sham 6-OHDA & $(n=6)$ & $93.42 \pm 6.0$ & $14.52 \pm 0.4$ \\
6-OHDA & $(n=8)$ & $85.41 \pm 4.4$ & $13.17 \pm 0.8$ \\
Depletion (\%) & & 9 & 9 \\
AC & & & \\
Sham 6-OHDA & $(n=6)$ & $126.93 \pm 8.3$ & $25.38 \pm 2.0$ \\
6-OHDA & $(n=8)$ & $63.44 \pm 8.1^{*}$ & $13.64 \pm 1.2^{*}$ \\
Depletion (\%) & & 50 & 46 \\
\hline
\end{tabular}

$a$ Values are in nanogram per milligram protein, mean \pm SEM.

${ }^{*} p<0.05$ (Student's $t$ test), significantly different from sham 6-OHDA group.

ent study is that the test appears sensitive enough to expose a deficit with less than a complete lesion of the caudate nucleus. Whether this performance deficit reflects a partial depletion of a large part of the caudate nucleus or a large depletion of one specific subregion remains to be determined.

Knowledge of the role of the corpus striatum in motor performance has a long history, dating from the introduction of the term "extrapyramidal motor system" (Wilson, 1912); the corpus striatum has been considered a possible substrate for a variety of neuorological disorders, such as Huntington's disease, tardive dyskinesia, and Parkinson's disease. Indeed, the main symptoms of Parkinson's disease (akinesia, rigidity, and tremor) are thought to be due to a loss of dopamine in the nigrostriatal dopamine pathway (Hornykiewicz, 1973).

However, Parkinson's disease is now known to involve decreases in dopamine function in more than simply the corpus striatum (Price et al., 1978; Javoy-Agid and Agid, 1980), and thus the specific contribution of the different dopamine projections to the function of the extrapyramidal motor system has been the subject of increasing inquiry. Similar questions can be asked concerning the role of the different dopamine projections in the behavioral action of dopamine-receptor antagonists (antipsychotic drugs) (Koob et al., 1984).

In the rat, the neurotoxin-induced lesion of the region of the nucleus accumbens (ventral striatum) produces decreases in motor activation caused by indirect sympathomimetics (Kelly et al., 1975), as well as decreases in the activation produced by some environmental contingencies (Koob et al., 1978; Robbins and Koob, 1980; Robbins et al., 1983). In contrast, neurotoxininduced lesions of the corpus striatum decrease the stereotyped behavior produced by indirect sympathomimetics, but can actually increase locomotor activity (Creese and Iversen, 1974; Kelly et al., 1975; Koob et al., 1984). In cats, local injections of haloperidol into the caudate nucleus produce deficits in the ability of the animals to respond to specific cues (Cools et al., 1976). These types of deficits and data showing profound sensorimotor neglect in rats with large dopamine depletions in the corpus striatum (Marshall, 1979) have led to the general hypothesis that the dopamine in the caudate nucleus has a role in integrating sensory and motor information for the initiation of complex motor responses.

The question remains as to whether the extrapyramidal motor system acts in concert in such a function, or whether the different parts of the extrapyramidal motor system function differentially on the basis of differential input and output. Anatomical data on corticostriatal projections based on studies of fiber degeneration in the neostriatum following cortical lesions showed that frontal-association cortex projected to the anterior caudate, whereas somatosensory and motor cortex projected to the posterior parts of the caudate in monkeys (Kemp and Powell, 1970). However, recent autoradiographic studies following tracer injections in localized parts of the cortex indicate that the association cortex projects throughout all anteroposterior subdivisions of the caudate (Goldman and Nauta, 1977; Selemon and Goldman-Rakic, 1985), and that the motor and premotor parts of the cortex have similar anteroposterior projections in the putamen in monkeys (Kunzle, 1975). This distribution of corticostriatal projections has not yet been shown in the rat. Thus, the deficit following depletion of dopamine in the posterior part of the caudate nucleus observed in this study may reflect an impairment in the processing of sensory information in order to produce a "motor" response. Exactly where this sensory information originates remains to be determined.

In summary, a selective depletion of dopamine in the posterior part of the caudate nucleus in rats causes a decrease in operant reaction-time performance characteristic of systemic dopamine-receptor blockade. Results suggest that partial lesions of dopamine in the caudate nucleus can produce subtle motor deficits that are not otherwise obvious and that dopamine in part of the caudate nucleus may be necessary for initiating a conditioned movement to a sensory cue.

\section{References}

Conde, H., J. F. Dormont, A. Schmied, and M. Benita (1978) Scheduled training of cats to a simple reaction time performance. J. Physiol. (Paris) 74: 439-446.

Conde, H., M. Benita, J. F. Dormont, A. Schmied, and A. Cadoret (1981) Control of reaction time performance involves the striatum. J. Physiol. (Paris) 77: 97-105.

Cools, A. R., H. A. J. Struyker-Boudier, and J. M. Van Rossum (1976) Dopamine receptors: Selective agonists and antagonists of functionally distinct types within the feline brain. Eur. J. Pharmacol. 37: 12831293.

Cooper, B. R., G. R. Breese, L. D. Grant, and J. L. Howard (1973) Effect of central catecholamine alterations by 6-hydroxydopamine on shuttle-box avoidance acquisition. Physiol. Behav. 9: 727-731.

Creese, I., and S. D. Iversen (1974) A role of forebrain dopamine systems in amphetamine induced stereotyped behaviour in the rat. Psychopharmacology 39: 345-357.

Evarts, E., H. Teravainen, and D. B. Calne (1981) Reaction time in Parkinson's disease. Brain 104: 167-186. 
Falk, J. L. (1969) Drug effects on discriminative motor control. Physiol. Behav. 4: 421-427.

Felice, I. J., J. D. Felice, and P. T. Kissinger (1978) Determination of catecholamines in rat brain parts by reverse-phase ion-pair liquid chromatography. J. Neurochem. 31: 1461-1465.

Fibiger, H. C., A. G. Phillips, and A. P. Zis (1974) Deficits in instrumental responding after 6-hydroxydopamine lesion of the nigro-neostriatal dopaminergic projection. Pharmacol. Biochem. Behav. 2:8796.

Fowler, S. C., K. E. Ford, S. E. Gramling, and G. L. Nail (1984) Acute and subchronic effects of neuroleptics on quantitative measures of discriminative motor control in rats. Psychopharmacology 84: 368373.

Goldman, P. S., and W. S. H. Nauta (1977) An intricately patterned prefrontocaudate projection in the rhesus monkey. J. Comp. Neurol. 171: 369-386

Hornykiewicz, G. (1973) Parkinson's disease: From brain homogenate to treatment. Fed. Proc. 32: 183-190.

Javoy-Agid, F., and Y. Agid (1980) Is the mesocortical dopaminergic system involved in Parkinson's disease? Neurology 30: 1326-1330.

John, E. R., and K. F. Killam (1959) Electrophysiological correlates of avoidance and conditioning in the cat. J. Pharmacol. Exp. Ther. 125: 252-275

Kelly, P. H., P. Seviour, and S. D. Iversen (1975) Amphetamine and apomorphine responses in the rat following 6-OHDA lesions of the nucleus accumbens septi and corpus striatum. Brain Res. 94: 507522.

Kemp, J. M., and T. P. S. Powell (1970) The corticostriate projection in the monkey. Brain 93:525-546.

Koob, G. F., S. J. Riley, S. C. Smith, and T. W. Robbins (1978) Effects of 6-hydroxydopamine lesions of the nucleus accumbens septi and olfactory tubercle on feeding locomotor activity and amphetamine anorexia in the rat. J. Comp. Physiol. Psychol. 92: 917-927.

Koob, G. F., H. Simon, J. P. Herman, and M. Le Moal (1984) Neuroleptic-like disruption of the conditioned avoidance response re- quires destruction of both the mesolimbic and nigrostriatal dopamine systems. Brain Res. 303: 319-329.

Kunzle, H. (1975) Bilateral projection from precentral motor cortex to the putamen and other parts of the basal ganglia. Brain Res. 88 . 195-209.

Marshall, J. F. (1979) Somatosensory inattention after dopaminedepleting intracerebral 6-OHDA injections: Spontaneous recovery and pharmacological control. Brain Res. 177: 311-324.

Price, K. D., T. J. Farley, and O. Hornykiewicz (1978) Neurochemistry of Parkinson's disease: Relation between striatal and limbic dopamine. In Advances in Biochemical Psychopharmacology, Vol. 19, F Cattabeni, C. Racagni, P. F. Spano, and E. Costa, eds., pp. 293-300, Raven, New York.

Robbins, T. W., and G. F. Koob (1980) Selective disruption of displacement behavior by lesions of the mesolimbic dopamine system. Nature 285: 409-412.

Robbins, T. W., D. C. S. Roberts, and G. F. Koob (1983) The effects of amphetamine and apomorphine upon operant behavior and schedule-induced licking in rats with 6-hydroxydopamine-induced lesions of the nucleus accumbens. J. Pharmacol. Exp. Ther. 224: 662-673.

Selemon, L. D., and P. S. Goldman-Rakic (1985) Longitudinal topography and interdigitation of corticostriatal projections in the rhesus monkey. J. Neurosci. 5: 776-794.

Spohn, II. E., L. Coyne, R. Lacoursière, D. Mazur, and K. Hayes (1985) Relation of neuroleptic dose and tardive dyskinesia to attention information-processing and psychophysiology in medicated schizophrenia. Arch. Gen. Psychiatry 42: 849-859.

Wilson, S. A. K. (1912) Progressive lenticular degeneration: A familial nervous disease associated with cirrhosis of the liver. Brain 34: 295509.

Winer, B. J. (1971) Statistical Principles in Experimental Design McGraw-Hill, New York.

Zis, A. P., H. C. Fibiger, and A. G. Phillips (1974) Reversal by L-dopa of impaired learning due to destruction of the dopaminergic nigroneostriatal projection. Science 185:960-962. 